\title{
Study on the Intercultural Communication Ability of English Teachers in Higher Vocational Colleges under the Background of International Education
}

\author{
Aimei Yang \\ Wenzhou Vocational \& Technical College, Wenzhou, China \\ 334710101@qq.com
}

Keywords: Intercultural communication; English teachers; Vocational colleges

\begin{abstract}
: with the continuous development of global economic integration, global cultural exchanges have also changed. Education also needs to be in line with international standards, contact with education resources in other places, and generate communication and collision between different cultures. In the context of current international education, teachers' intercultural communication ability is indispensable. Intercultural communication not only needs communication at the language level but also involves culture and its related elements. In this study, the current situation of intercultural communication ability of English teachers in higher vocational colleges and the reasons for this situation are mainly discussed. Based on the actual situation of teachers in higher vocational colleges, the effective strategies of cultivating their intercultural awareness are put forward, so as to offer suggestions for improving the overall level of intercultural communication ability of English teachers in higher vocational colleges.
\end{abstract}

\section{Introduction}

"Intercultural communication" refers to the communication between people with different cultural backgrounds, the communication between native speakers and non-native speakers, and the communication between people with different language backgrounds. The basic idea is that people from different cultural backgrounds interact with each other in a very complex process. In communication, people will have different understandings of the same thing due to different cognitive behaviors, values and thinking patterns under different cultural backgrounds. Failure to understand these differences may lead to communication failure. Therefore, to avoid such situation, the research on intercultural communication is introduced into teaching so that teachers can improve their awareness of intercultural communication, always pay attention to the cultivation of their intercultural communication ability, reduce communication conflicts and carry out English teaching smoothly.

\section{Literature Review}

The purpose of foreign language teaching is to cultivate talents of intercultural communication. Today, with the globalization of the world economy and cultural diversity, the importance of the 
cultivation of intercultural ability of talents becomes more and more obvious. More and more attention has been paid to cultural teaching in foreign language teaching. Chinese and foreign scholars have carried out many discussions and studies, and the cultural teaching development in various countries has presented an unbalanced situation. In China, although people's understanding of intercultural communication has been improved, the concrete implementation and effectiveness are far from satisfactory.

Tatsukawa (2017) proposed the framework of cultural contrast, which can not only help teachers understand the difficulties in cultural learning in advance, but also improve students' cultural awareness. However, he only considered the observable behavior level, but did not make comparative analysis of relevant important cultural elements such as values and world views [1].

Czura (2016) believed that culture has two levels, namely formal culture and deep culture. The differences between them can be judged from whether the cultural subject can realize or observe the role of culture. Although the definition of culture on two levels is quite vague, he had a comprehensive definition of culture and considered the needs of foreign language teaching. He also stressed that cultural teaching should be involved in the whole process of foreign language teaching, and different emphases and teaching methods should be determined at different stages [2].

Rakhimova (2016) proposed the "Emergent Model" cultural analysis mode. He determined that there were 32 main contents and features which constituted the social and cultural system, and he summarized them into four sub-systems. This analysis model comprehensively and thoroughly analyzes the contents contained in culture, sorts out and classifies the cultural contents which are originally disordered and difficult to grasp, so as to help people better understand culture and control and operate the cultural contents in foreign language teaching [3].

Based on the mode of cultural analysis of Rakhimova, Fang (2017) determined the overall goal and other objectives of cultural learning, and introduced some methods used in cultural teaching, such as culture capsules, culture clusters, and culture assimilators. He also discussed how to evaluate cultural learning and pointed out the direction for cultural teaching practice [4].

Javdani (2016) clarified the important position of social concept in language teaching in his important works. In a paper on multidimensional foreign language courses, he proposed a new curriculum model consisting of four parts, including cultural syllabus [5].

Budden (2017) put forward the assumption of "cultural sensitivity", and he began to pay attention to the "internalization process" and "psychological changes" of foreign language learners. He believed that culture exists both in cultural products and forms, and in the process in which culture is used. People often use their own cultural values and social norms to negotiate with communicative objects in various social situations. Therefore, foreign language teaching should not only impart cultural knowledge to students, but also help students to make use of language and culture to create meaning and negotiate, so as to achieve mutual understanding. Students should have the opportunity to conduct the ethnographic practice to modify their negative perceptions of other cultural groups and promote the formation of positive impressions [6].

Walker (2018) advocated the language and culture teaching of the multi-cultural interaction mode, which broke through the simple "cultural introduction" teaching of foreign language in the past, made the mother tongue and target language equal in importance, formed the "two-way interaction", and corrected the previous phenomenon of "emphasizing the cultural teaching content and neglecting the cultural teaching process" [7].

The vigorous development of American language and culture teaching further confirms people's cognition of language and culture teaching. As Sándorová (2016) said, culture defines the content and form of language itself, and it is difficult to achieve the result of flexible use of language without understanding the cultural background of language formation. Cultural knowledge and cultural awareness of relevant languages can make language use more proficient and appropriate. 
Therefore, cultural teaching is not a dispensable skill, but the core of language teaching [8].

It can be concluded that more and more attention has been paid to the study of intercultural communication in recent years. Many experts and scholars have done a lot of research on intercultural communication from different perspectives and made many achievements. Still, there are problems. The papers and monographs that study the intercultural communication ability are disproportionate in quantity and depth from its importance and actual needs.

\section{Methodology}

Taking the intercultural communication ability model including cognition, emotion and behavior as the theoretical framework, the questionnaire survey and teacher interview are conducted for the intercultural teaching in Wenzhou Vocational \& Technical College. Through in-depth analysis of the questionnaire and interview results, the current situation and existing problems of intercultural foreign language teaching are studied from three levels of cognition, emotion and behavior. Questionnaire and interview are the important research methods of this study. The two are closely linked and corroborate each other, and they work together to study English intercultural teaching in higher vocational colleges and provide data information for further research.

The questionnaire surveys the intercultural teaching of English teachers in Wenzhou Vocational \& Technical College to understand the concept of intercultural teaching and the mastery of cultural knowledge of teachers, the attitude, understanding and attention to cultural teaching, the methods, time and contents of intercultural teaching. By analyzing the statistical data, the problems of teachers in intercultural teaching and the main factors influencing intercultural teaching are found.

The interviewees are English teachers from Wenzhou Vocational \& Technical College. In-depth interviews are conducted to understand the teachers' intercultural training, their understanding of intercultural teaching, their understanding of intercultural communication ability, and the implementation of intercultural teaching, as well as their views on exam-oriented education and cultural quality education. By analyzing and sorting out the interview data, the problems and shortcomings of English intercultural teaching in higher vocational colleges are further found.

\section{Results and Discussion}

\subsection{Teachers' intercultural comprehensive qualities need to be improved}

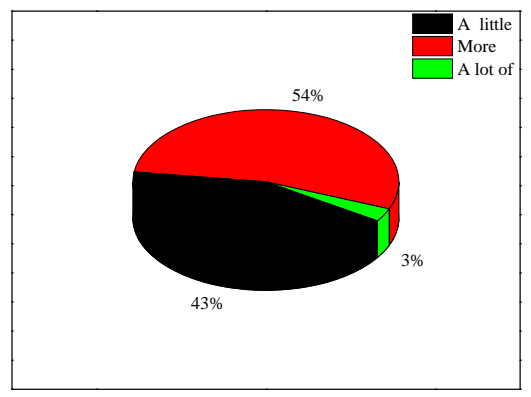

Figure 1 Teacher's own cultural knowledge reserve

The teacher's cultural quality reserves are weak. As shown in figure 1, in the test of teachers' knowledge reserve of intercultural communication in this study, $54 \%$ of teachers think that they have "more" cultural knowledge reserves, 43\% think that they have only "a little" cultural knowledge reserves, and only 3\% think that they have "a lot of" cultural knowledge. These data 
indicate that teachers don't know much about intercultural communication and don't have sufficient knowledge of culture. In the teacher interview, an old teacher who has been teaching English for 18 years said with deep feeling "Recently, I have watched several American TV series, and I feel very sad. After teaching English for so many years, I find that I know very little about English culture”.

The statistical results show that the teachers are not well prepared for cultural teaching, the average level of their own cultural knowledge is low, and their own cultural quality is insufficient, which can't guarantee the effective implementation of cultural teaching. The reason is that teachers lack intercultural practice environment and cultural training. The survey results of teachers going abroad show: among the 36 teachers surveyed, the shortest length of English teaching is 3 years, the longest is 27 years, and the number of teachers with 10 years of teaching is the largest, accounting for $25 \%$ of the total number of teachers. As shown in figure 2, 21 teachers have gone abroad, accounting for $58.33 \%$ of the total number of subjects. The number of teachers who have no experience of going abroad is 15 , accounting for $41.67 \%$ of the total number, as shown in table 1 . It can be concluded from figure 2 and table 1 that most English teachers have difficulty in obtaining the opportunity of overseas training during their years of English teaching. Even if they have the opportunity, the time spent outside is too short to achieve the purpose of cultural training and cultural experience. The lack of cultural training is the main reason for the shortage of teachers' cultural reserve.

Table 1 Statistical table of the situation of teachers going abroad

\begin{tabular}{|l|l|l|l|l|}
\hline & & $\begin{array}{l}\text { Number of } \\
\text { people }\end{array}$ & Duration & Percentage \\
\hline \multirow{2}{*}{$\begin{array}{l}\text { Experience of } \\
\text { going abroad }\end{array}$} & Yes & 21 & & $58.33 \%$ \\
\cline { 2 - 5 } & No & 15 & & $41.67 \%$ \\
\hline Country & Canada & 20 & One month & $95.24 \%$ \\
\cline { 2 - 5 } & Europe & 1 & Half a month & $4.76 \%$ \\
\hline
\end{tabular}

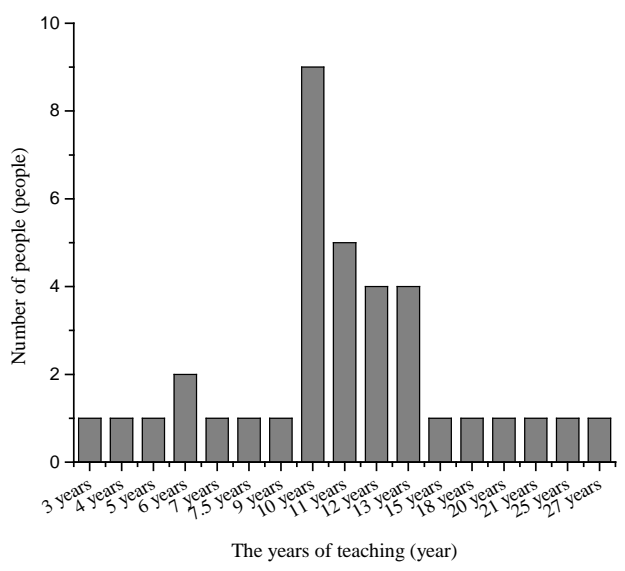

Figure 2 Statistics of teacher's teaching year

From the results of questionnaires and interviews, it can be concluded that teachers themselves have few opportunities to use English for intercultural communication, their cultural sensitivity is not strong, and their ability of intercultural communication is weak. Studying abroad is just an impossible dream for most Chinese English teachers. Although the number of English teachers who have the opportunity to study abroad has increased in recent years, in general, the language and culture knowledge of Chinese English teachers basically comes from the study in China. Because of this, many English teachers have a very superficial understanding of the culture of English-speaking 
countries and the culture of the rest of the world. Most of them are fragmentary second-hand information, which is not systematic, but may be some wrong understanding or prejudice. On the other hand, teachers don't pay attention to the accumulation of cultural knowledge in the daily living environment or learning environment, which is mainly caused by the language circle dominated by Chinese and the talent cultivation mechanism of exam-oriented education.

\subsection{Teachers' understanding of intercultural teaching doesn't conform to the teaching practice}

Teachers' understanding of intercultural teaching is not comprehensive and profound. The following is a survey of teachers' opinions on whether cultural knowledge contributes to the improvement of students' intercultural communication ability. The results show that teachers generally believe that the learning of cultural knowledge is helpful to the improvement of intercultural communication ability, and more than $50 \%$ of teachers think it is "very helpful", as shown in figure 3.

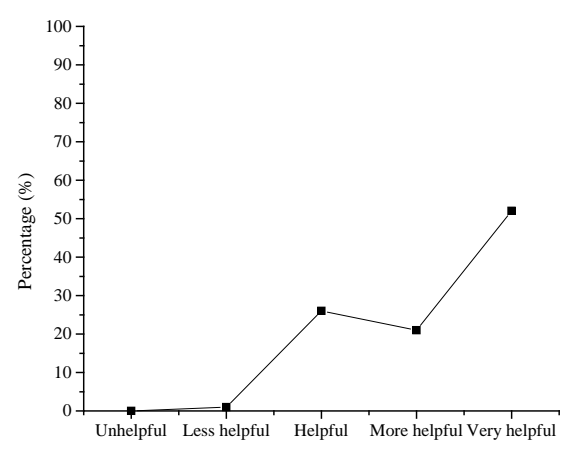

Figure 3 The survey of whether cultural knowledge contributes to the improvement of students' intercultural communication ability

As shown in figure 4, 20 teachers include "cultural awareness/knowledge" in the teaching plan, accounting for 55.6\%; 2 teachers don't include "cultural awareness/knowledge" in the teaching plan, accounting for 5.6\%; 14 teachers sometimes include "cultural awareness/knowledge" in the teaching plan, accounting for $38.8 \%$. It can be concluded that $55.6 \%$ of teachers regard cultural teaching as regular teaching content, $38.8 \%$ think that cultural teaching content is optional, and more seriously, 2 teachers ignore cultural teaching.

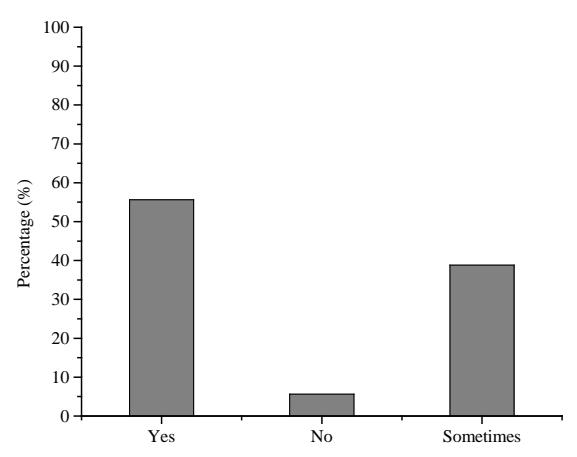

Figure 4 Survey on whether teachers include “cultural awareness/knowledge” in teaching plans Teachers have a deep understanding of intercultural communication knowledge and intercultural 
teaching, that is, they have realized the importance of intercultural communication knowledge and intercultural teaching, and generally believe that language skills training and cultural knowledge learning are equally important, but there is a serious disconnection between cognition and teaching practice. It can be concluded that most teachers understand and support the cultivation of cultural teaching and intercultural communication ability in foreign language teaching, but they don't have a thorough understanding of the intercultural foreign language teaching ideas, and they are afraid of increasing the burden on students and themselves, and they don't know how to carry out intercultural foreign language teaching.

Teachers' choice of intercultural teaching mode is too single. It can be concluded from figure 5, in the process of intercultural knowledge infusion, the number of teachers adopting three methods is up to 12, accounting for $33.3 \%$; there are 8 teachers adopting four methods, accounting for $22.2 \%$; there are 7 teachers adopting two methods, accounting for $18.4 \%$. From the perspective of the proportion of each option, teachers' choice of methods for imparting intercultural knowledge is quite different, reflecting that teachers' choice mode of intercultural teaching is not ideal, the teaching mode is too monotonous, and the cultural teaching mode and method are too old.

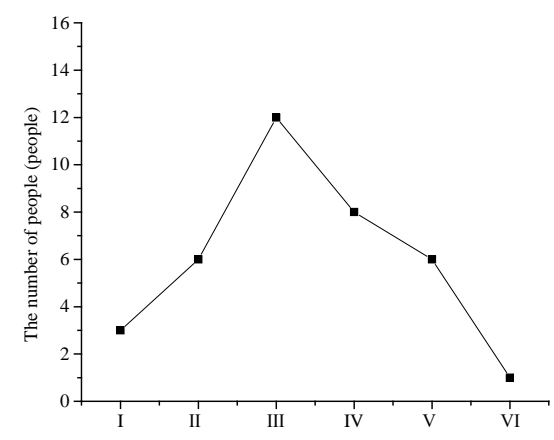

Figure 5 The choice of intercultural knowledge teaching method of teachers

Notes:

I: Oral introduction, supplemented by pictures and texts, playing related videos or music, citing literary works, allowing students to discuss and compare, one of them

II: Oral introduction, supplemented by pictures and texts, playing related videos or music, citing literary works, allowing students to discuss and compare, two of them

III: Oral introduction, supplemented by pictures and texts, playing related videos or music, citing literary works, allowing students to discuss and compare, three of them

IV: Oral introduction, supplemented by pictures and texts, playing related videos or music, citing literary works, allowing students to discuss and compare, four of them

$\mathrm{V}$ : Oral introduction, supplemented by pictures and texts, playing related videos or music, citing literary works, allowing students to discuss and compare, five of them

VI: Oral introduction, supplemented by pictures and texts, playing related videos or music, citing literary works, allowing students to discuss and compare, select all

Teachers don't properly handle language skills training and cultural knowledge learning in the teaching process. It can be concluded from figure $6,58.3 \%$ of teachers attach equal importance to both language skills training and cultural knowledge learning in the teaching process; $36.1 \%$ of teachers mainly focus on reading skills, while the dissemination of cultural knowledge is supplemented; $5.6 \%$ of teachers focus on the dissemination of cultural knowledge, and the training of reading skills is secondary. 


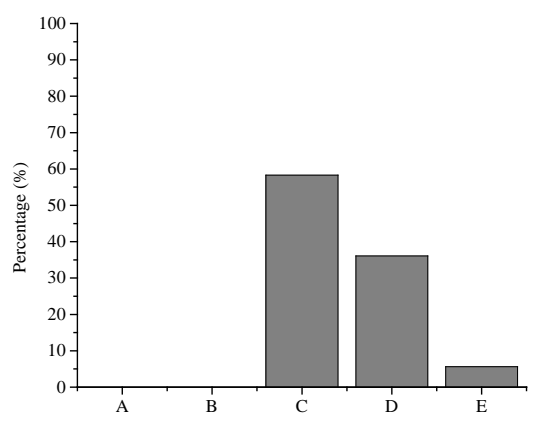

Figure 6 The practice of teachers in dealing with language skills training and cultural knowledge learning

Notes:

A: Focus only on reading skills training

B: Only care about the transmission of cultural knowledge

C: Both

D: Reading skills training is the main, and cultural knowledge is the second

E: Cultural knowledge is the main, reading skills training is the second

Teachers' cultural teaching takes up less time. From the data distribution of the teacher culture teaching occupation time in Figure 7 , it can be concluded the degree to which teachers attach importance to cultural teaching in practical teaching. 63.9\% of teachers have less than 10 minutes of cultural teaching, $80.6 \%$ of teachers don't exceed 15 minutes, and only $19.4 \%$ of teachers have 20 minutes of teaching time, accounting for only $44.44 \%$ of actual teaching time. Teachers' cultural teaching takes less time in the classroom, with an average of about 10 minutes (45 minutes for a class), which can't meet the needs of cultural teaching.

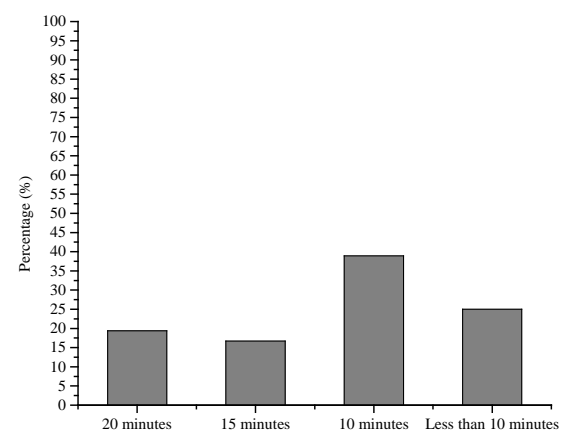

Figure 7 Cultural teaching time

It can be concluded that teachers don't know how to combine cultural teaching with language teaching in actual teaching. Cultural teaching is in a state of arbitrary play and disorder. In the interview, teachers generally report that the teaching content of each unit would take two weeks (four class hours per week) to complete. Teachers feel that it is difficult to finish the language teaching task within the prescribed period, and it is even more difficult to increase the cultural content, thus ignoring the ability training of intercultural communication. Teachers' implementation of cultural knowledge in the actual teaching is not in sync with their understanding of the importance of cultural teaching, and the lack of cultural teaching time further proves the disconnection between knowledge and reality. Teachers still focus on language teaching in 
accordance with the convention, and intercultural teaching is purely formal.

Teachers' understanding of the meaning and purpose of cultural teaching is not comprehensive enough, which directly leads to a serious imbalance in the teachers' culture teaching methods. The method lacks flexibility and diversity, and the single phenomenon is serious, which is not conducive to arousing students' interest and enthusiasm in learning. The irrationality of the time arrangement of teaching makes cultural teaching a dispensable accessory of language teaching.

To sum up, there are many problems in the intercultural teaching of higher vocational college, which can't adapt to the increasingly frequent demands of today's world. Therefore, it is necessary to carry out teaching reform, study effective countermeasures, and build a practical and feasible intercultural communication ability cultivation system.

\section{Conclusion}

The ultimate goal of English intercultural teaching in higher vocational colleges is to cultivate students' intercultural communication ability, while higher vocational teachers are the bridge and link to achieve this goal. To strengthen higher vocational teachers' intercultural communication ability and the training of intercultural teaching method, in the process of training students, teachers in higher vocational education can not only strengthen the students' language skills training, but also strengthen students' ability to communicate in the specific situation of communication training, so that the students can not only recognize specific language forms but also use English freely in specific situations. In the teaching process, teachers should also strengthen students' cognition of different cultural differences and values, improve students' ability to understand and recognize different cultures, so that in the future intercultural communication, students' discourse can not only conforms to the correct language form and language habit, but also conforms to cultural habit, so as to seek the balance between "keeping oneself" and "adapting to others". Both textbook compilation and actual teaching process should contain these contents.

Teaching methods should be more diversified. Teaching and lecture can be adopted to strengthen students' cognition of relevant knowledge. In addition, role playing, critical event analysis and case analysis should be adopted to enable students to think through observation in real cases and situations, discover language and cultural differences and understand the pragmatic and cultural differences that lead to misunderstandings, problems and conflicts, explain the cultural differences that affect communicators' interpretation and understanding in actual cases, help learners find and solve problems caused by cultural differences, and cultivate students' correct use of communication strategies, attitudes toward other cultures, and empathy ability.

\subsection{Enrich the teaching knowledge of English teachers in higher vocational colleges}

Higher vocational English teachers play an extremely important role in students' English learning. This special identity directly affects their activities in the classroom and the cultivation of students' learning habits. Therefore, higher vocational English teachers should constantly strengthen their own learning and establish the concept of lifelong learning and development; in education teaching, teachers should constantly summarize and reflect, absorb scientific teaching ideas, adopt advanced teaching mode, promote themselves to learn in teaching research, and make beneficial exploration for foreign language learners and teaching strategies by combining practice.

To be a good classroom director, higher vocational English teachers must strengthen their self-cultivation and comprehensively improve their quality. In addition to constantly enriching their professional knowledge, they should also do their best to serve the needs of teaching and enrich relevant knowledge of teaching. Teachers can acquire the latest education news and advanced teaching knowledge through listening to English programs, reading English newspapers, books and 
magazines, and browsing education website.

\subsection{Enhance teachers' awareness of intercultural teaching}

English teaching is both language teaching and culture teaching. Teachers should prepare not only knowledge but also culture when preparing for lessons. On the one hand, through English textbooks, teachers can gradually introduce the background knowledge of Chinese and western society and culture to the students, let students understand the differences between English culture and Chinese culture, and enhance students' awareness of intercultural communication; on the one hand, free talk is used to give cultural lectures to students.

The cultivation of intercultural awareness is a comprehensive project. Fundamentally speaking, it is the cultivation of cultural quality rather than pure language training or communication skills training. The way for English teachers to improve their cultural literacy is to receive professional training, learn English culture courses, and have an in-depth and detailed understanding of the history, culture, tradition, customs, lifestyle and even life details of English countries, so as to create conditions for improving English teaching and handle the relationship between language teaching and cultural teaching.

\subsection{Improve teachers' classroom teaching methods}

Quality education is the education of the subject's harmonious development and the education of the open. Therefore, it is necessary to create a relaxed and harmonious learning atmosphere. The "controlled" teacher-student relationship of command, threat and punishment will suppress students' desire for language communication and hinder students' initiative in learning and the development of innovative thinking. Therefore, an open teacher-student relationship that maintains a democratic, equal, emotionally exchanged, and collaborative effort with students in the classroom should be advocated.

Give full play to the dual role of teachers and students. Follow the teacher-led and student-centered teaching policy. The classroom always revolves around mobilizing students to fully carry out activities.

Help students form good study habits. Higher vocational teachers should be good at using teaching skills to motivate students to learn, so that they can gradually develop the good habits of learning English, practicing English and acquiring English.

Cultivate and control the emotional factors of teachers and students. In the process of foreign language learning, learners may experience anxiety, depression, and restlessness due to external factors. As the organizer of teaching activities, foreign language teachers should pay attention to the emotions of foreign language learners from time to time.

Establishing the teaching view of intercultural communication English, higher vocational teachers should understand the comparative significance of Chinese culture and western culture represented by English at the language level, nonverbal communication, thinking mode, narrative structure and social language.

Higher vocational teachers should also properly handle the role of the mother tongue system in learning. Through the integration of the common core of language and culture and the comparison of different parts, the subliminal system of students' native language culture becomes a positive, positive and constructive frame of reference, so that English becomes explicit, easy to feel and understand in the comparison, that is, positive transfer occurs. 


\section{References}

[1] Tatsukawa, K. (2017). A study on japanese high school teachers' use and instruction of communication strategies in english. Arele Annual Review of English Language Education in Japan, 19, 181-190.

[2] Czura, A. (2016). Major field of study and student teachers'views on intercultural communicative competence. Language \& Intercultural Communication, 16(1), 83-98.

[3] Rakhimova, A. E., Yashina, M. E., Mukhamadiarova, A. F., \& Sharipova, A. V. (2016). The development of sociocultural competence with the help of computer technology. Interchange, 48(1), 1-16.

[4] Fang, G. F. (2017). International cultures in the framework of world englishes: what should efl teachers do. Journal of Asia Tefl, 8(1), 111-137.

[5] Javdani, L., \& Jadidi, E. (2016). The impact of knowledge of multiword units on pragmatic knowledge of iranian efl learners. Theory \& Practice in Language Studies, 6(4), 757.

[6] Budden, Michael C.|Budden, Connie B.|Lopez, Tará Burnthorne. (2017). Enhancing cross cultural communication in the marketing classroom: a case approach. Journal of International Education Research, 13(1), 45.

[7] Walker, D. (2018). Improving korean university student efl academic writing with contrastive rhetoric: teacher conferencing and peer response can help. Journal of Asia Tefl, 3(4), 71-111.

[8] Sándorová, Z. (2016). The intercultural component in an efl course-book package. Journal of Language \& Cultural Education, 4(3), 178-203. 